\title{
Economic Status, Community Danger and Psychological Problems among South African Children
}

\author{
Oscar A. Barbarin and \\ University of North Carolina \\ Linda Richter \\ University of Natal
}

\begin{abstract}
An extensive literature links community violence and poverty in the US to psychological difficulties in children. To test the cross-national generalizability of these relationships, 625 young, South African mothers residing in black townships with different levels of community danger and material hardship rated their 6-year-olds on emotional functioning and behavioral problems. Most mothers were African, employed and of low educational attainment. Community danger was confirmed as a risk factor for anxiety, depression, aggression, opposition and low affability in children. A composite measure of socioeconomic status as indexed by education and job status was unrelated to behavioral and emotional adjustment. However, children experiencing material hardship had fewer problems related to behavioral self-control than children in families with greater access to material resources.
\end{abstract}

\section{Keywords}

African children; psychological measures

\begin{abstract}
Material deprivation associated with low socioeconomic status (SES) such as poverty, hunger or homelessness is so patently aversive that claims about its negative impact seem obvious and unassailable. Nevertheless, such claims have only recently been subjected to systematic empirical tests, in research mostly conducted in the US. For the most part, the results of these tests confirm common sense predictions about the risks such deprivation poses to children's psychological well-being. For example, Duncan et al. (1994) have shown that behavioral and emotional difficulties occur more frequently among poor than non-poor children. Poverty has been associated with elevated levels of depressive symptoms (Hammen and Rudolph, 1996). Even though poor children may not meet DSM IV criteria for diagnosable emotional disorders more frequently than non-poor children, they report symptoms classified within the syndromes of depression and anxiety more frequently than children from economically advantaged backgrounds (Gore et al., 1993; Valez et al., 1989). An even stronger case has been made linking poverty to children's conduct problems and academic failure than has been made for emotional problems (Capaldi and Patterson, 1994; Felner et al., 1995; McLoyd, 1998). Poor children are more likely to be affected by substance abuse, teen pregnancy, juvenile crime and premature termination of education than children whose lives are not touched by poverty (Dryfoos, 1990). Of all the domains, evidence of impact on cognitive and academic functioning is most striking, particularly when poverty occurs early in life (Brooks-Gunn and Duncan, 1997). Evidence of the adverse
\end{abstract}

\footnotetext{
Copyright $\odot 2001$ SAGE Publications.

Mailing address: Oscar Barbarin, 114 Ivy Brook Lane, Chapel Hill, NC 27516, USA. [email: barbarin@unc.edu] .
} 
impact of poverty on children's development is so compelling that international organizations consider it one of the most serious threats to the well-being of the world's children (United Nations, 1998).

Violence closely follows poverty as a pervasive threat to children's well-being. Around the world violent conflict resulting from ethnic and political strife have become disturbingly commonplace in the lives of children (Cairns and Dawes, 1996). Although war and political strife are especially worrisome, children are just as often placed at risk for psychological difficulty by criminal, familial and community violence (Guerra et al., 1995). For example, perceptions of neighborhood as threatening and dangerous were correlated with depression, anxiety, oppositional defiant disorder and conduct disorders in children and adolescents (Reinherz et al., 1993). Witnessing and hearing about conflict within the family were also highly correlated with distress (Osofsky et al., 1993). Young children may be more susceptible than adolescents to adverse impact of violence exposure. For example, adolescents showed distress only when violence occurred to some-one they knew. However, young children exhibited mental health problems even if exposure to violence was indirect (Richters and Martinez, 1993b). Osofsky and colleagues (1993) concluded that children exposed to violence experienced: (1) difficulty concentrating because of lack of sleep and interest of imagery; (2) significant impairments because of avoidance of intrusive thoughts; (3) anxious attachments to mothers, being fearful of leaving them or sleeping alone; (4) aggressive play, becoming more aggressive, imitating behaviors they have seen; (5) acting tough to deal with fear and developing counter-phobic reactions; (6) acting in an uncaring manner as a way of dealing with loss and hurt; and (7) avoiding some activities out of fear of re-experiencing traumatic events.

Outside the US, Robertson and Berger (1994) report similar reactions to violence among children in South Africa. They reported that children living in dangerous and poor shack communities displayed stress-related symptoms at significantly higher rates than children living in relatively more secure formal housing communities. However, it is unclear how much the observed effects are attributable to SES and how much to violence. The ubiquity of urban poverty and community violence in South Africa makes it a good location in which to examine the relative effects of poverty and violence on young children. Segregated housing for blacks resulted in high- and low-SES families living in proximity to one another. As a result, the likelihood of violence in South African neighborhoods was more strongly associated with political and interethnic conflict than economic factors as in American neighborhoods. Thus it is possible to examine separately the effects of household SES and community danger on child outcomes.

In addition, most of our knowledge about psychological effects of SES and violence are based on studies of adolescents, even in South Africa (Burman and Reynolds, 1986; Straker, 1992). Little is known about whether young children are similarly affected and about how early in life these psychological effects emerge. To address this gap in our knowledge we first adapted a mental health assessment originally designed for use with a US sample. We used the subsequent assessment to evaluate the effects of economic status and community danger on the psychological functioning of South African preschool children.

The available evidence supports predictions that both poverty and violence will be related to behavioral and emotional problems of South African children. Specifically, children from low-SES families and those living in communities rated as dangerous are likely to score higher on measures of behavioral and emotional problems than their counterparts.

Consistent with findings in the US, it is expected that effects will be greater for externalizing problems than for internalizing problems. However, in light of the frequent co-occurrence of poverty and violence it is not clear whether the contributions of poverty and violence to the 
prediction of children's adjustment problems are similar or distinctive, independent or overlapping, and additive or duplicative.

\section{Methods}

The data reported here were collected as a supplement to the Birth-to-Ten Project (BTT), a longitudinal investigation of the effects of urbanization on the development of a cohort of singleton births, occurring during the 7-week period between 23 April and 7 June 1990. Children $(N=3275)$ born during this period were identified through antenatal clinics and birth records. Participation in the study was limited to permanent residents within the metropolitan Johannesburg/Soweto area. In this way, the original sample included persons classified under the Apartheid system as white (e.g. English, Afrikaans-speaking, Jewish and persons of other European ancestry); Indians (i.e. descendants from immigrants from South Asia or the Indian subcontinent); Africans (persons descended from the original inhabitants) and Coloreds (persons of mixed heritage which involved some combination of the other groups). Under the current regime, black is being used to refer collectively to non-white population groups (African, Colored and Indian) who were subjected to political oppression. Nevertheless, the Apartheid era categories are still in use today in spite of the push toward non-racialism because the group categories are a powerful part of personal identity and are still linked to economic status. Within the metropolitan Johannesburg/Soweto area, 74 percent of births occur to persons previously classified as Africans, 12.5 percent to whites, 10.0 percent to Coloreds and 3.5 percent to Indians. Extensive baseline data on physical growth, psychological development and family life were collected within the first year of life and in follow-up data waves in 1992, 1994 and 1995. Attrition from the original sample of births occurred because, as previous studies have shown, about 20 percent of births are to mothers from rural areas who move to urban areas not for the purpose of permanent residence but to gain access to medical care not available in rural areas. An additional 10 percent attrition was attributable to a traditional practice of sending children to rural areas to be raised within the extended family. Less than 5 percent attrition occurred as a consequence of death of child, migration by the entire family and a very small number of refusals. By 1995 a minimum of two data points were obtained on about 70 percent of the total birth cohort children.

\section{6 study sample}

The goal of this supplemental study was to gather data by which to characterize the relationship of biological and social risks to the behavioral and emotional development of children in black urban townships. This required psychological data in much greater depth than could be included in the core data instrument administered to the entire birth cohort. However, limitations of time and financial resources made it impossible to sample the entire cohort. Consequently, the study aimed to recruit 700 participants in black townships. Because the data were also intended for longitudinal analyses, the criteria for inclusion in the study consisted of residence in a black township, and availability of complete data at all four data collection points. In all, 750 children met these criteria for our study, and 625 (83 percent) were successfully interviewed. Reasons for non-participation included death, moving out of the study area, inability to locate mother and language difficulties. Refusals to participate were less than 1 percent. The data reported here were collected between January and April 1996. Comparisons of this 1996 subsample with those of the entire black cohort show that the groups are closely matched demographically and do not differ with respect to gender, population group, area of residence, language or age of mother (Barbarin and Khomo, 1997).

Table 1 presents the study sample distributions on key demographic variables. The sample is primarily African (90.5 percent) but is evenly divided by gender. The typical child in this 
sample was born to a relatively young, single, working mother with low educational attainment. The median age of sampled mothers is 25 and most ( 79.4 percent) were in the work force. The median household size was 7 but only 25 percent had more than one biological sibling. Most lived within multigenerational households and 34 percent resided with their biological fathers.

\section{Measures}

\section{Community danger}

Community danger is based on assessments of community experts using a five-point scale from very safe, to very dangerous. The experts included people such as taxi drivers and community health workers who possessed knowledge of the rated communities based on their long time residence and because their work required them to move about in the targeted communities. Raters independently sorted communities into five categories from 1 (most safe) to 5 (most dangerous). Communities rated as dangerous are characterized by high levels of interpersonal violence. They are likely to be dominated by gangs of thugs who pose a threat to safety. Household robberies and street violence are commonplace. Residents often feel unsafe being out after nightfall. Non-residents often feel unsafe entering the community even during the day. In effect, the ratings are subjective appraisals of the likelihood of being a victim or indirectly experiencing violent events such as: physical threat or intimidation; shooting; stabbing; injury; sexual assault; murder; mugging; car hi-jacking; forced entry into a home; or robbery. The sources of community violence reflected in these ratings ranged from interethnic conflict motivated by economic competition to intimidation inspired by criminal activity and juvenile gangs (Barbarin and Richter, 2000). These ratings of ambient or general community danger proved to be reliable and correlated significantly with other sources of information on violence at the community level: reported incidents of political violence by the Human Rights Committee and the BTT interviews. But communities were not all the same with respect to their ambience of violence. While some communities were perceived as relatively tranquil and identified as safe, others became well known as denizens of violent activities that threatened visitors and residents alike. The latter were to be avoided if possible, and if necessary entered only under conditions of extreme vigilance. Residents of these communities were more likely to keep to themselves, and protect their children from potential harm by keeping them nearby and supervising them closely.

Estimates of interrater agreement average above .70 (Cohen's kappa). Kappa provides a very conservative estimate of intercoder agreement on multilevel ratings by correcting for chance agreement. The ratings reflect a wide variation among communities with respect to perceptions of how safe or violent they are. Expert rating scores correlated significantly with documented incidents of political violence (Pearson $r=.24 ; p \leq .01$ ) Community danger scores correlated significantly with objective data on killings and injuries, and other forms of violence in the community collected by the Human Rights Committee in Johannesburg. Thus the ratings are an index of threats from humans and not from ecological dangers such as from pollution and toxins. On the basis of these ratings, communities were classified for the purposes of the analyses included in this report as safe $(1,2)$ or unsafe $(3,4,5)$.

\section{The Household Economic and Social Status Index}

Early conceptions of SES often based on occupational status and education were intended to capture differences in the financial and social resources of a household (Hollingshead, 1957). This approach was justified first by the historical association between income and occupational status. Second, different levels of education are typically associated with distinctive patterns of values, access to information and lifestyles. These in turn influence 
functions such as problem-solving and child socialization. Changes in the relationship between occupational status and income, unreliability of self-reported income and the trend toward multi-wage-earner households have led to the use of multiple indicators to gauge SES. Thus, in addition to education and occupation, formulations of living standards and SES have been expanded to include material consumption, assets or wealth and family structure (see, for example, Entwistle and Astone, 1994). Accordingly, this study uses the Household Economic and Social Status Index (HESSI; Barbarin and Khomo, 1997), a selfreport measure that combines multiple indicators of the material and social resources available to South African households. In addition to maternal education and occupation of the principal wage-earner, these indicators include material resources such as financial assets (home ownership, savings, life insurance), security and adequacy of the food supply for children, type of housing, monthly utility expenses and possession of consumer goods such as televisions, refrigerators and automobiles. Because the index is used to characterize the material and social environment of the environment in which a child is raised, these SES scores reflect the status of a household rather than an individual such as the mother. The distributions of scores for occupational status, social status, housing and consumption for the sample in this study correspond closely to distributions of representative samples of urban South African blacks reported by the World Bank (1994). This similarity strengthens assumptions about the generalizability of findings to an urban black population in the Johannesburg/Soweto area.

Factor analysis of these indicators yielded two stable factors: (1) material consumption and (2) capital (social and financial). Details of the factor analysis and the computation of the two scales are presented in Barbarin and Khomo (1997). The material consumption factor is a linear combination rating of housing quality (e.g. private home with toilet and water at the high end and shack at the low end), number of consumer goods (car, refrigerator, microwave, telephone, television, video recorder and washing machine), and monthly expenditures for electricity (monthly payment: R500). Theoretically, consumption is a measure of standard of living or the material adequacy/deprivation experienced by a household. The material consumption indicators are selected to represent a broader universe of material goods needed in daily living. Thus scores on the material consumption scale indicate the relative material deprivation endured or advantage enjoyed by members of a household. Accordingly, a family low on material consumption might be living in a single room, garage or shack, and have none or few of its material needs met. Low consumption scores may mean living in a galvanized tin or cardboard shack without toilet, running water, electricity, heat or refrigerator. It may mean travelling to most places on foot and occasionally a public van or train when money is available (Barbarin and Richter, 2000). It may mean enduring the bitter cold during winter and suffocating heat in the summer. Children in households low in material consumption may lack toys, shoes, a warm coat, transportation to medical facilities and medicine when sick. They must rely on candlelight to do homework at night and have to sleep upright in a chair during rainy seasons because the mud floor of their shack is flooded.

The social and financial capital factor combines financial assets, adequacy of food supply, mother's education and occupational ranking of the primary wage-earner. Raw scores for these factors are transformed into standardized scores with a mean of 50 and a standard deviation of 10. A total SES score is obtained by combining the raw scores for consumption and capital and converting to a standard score.

\section{SES group assignment}

A three-level categorical variable was developed for each of these standardized SES scores (material consumption, capital and total SES). This was accomplished by dividing the sample into three groups: low (standard score $>45)$, moderate (standard score $=45-55$ ) and 
high (standard score < 55). Group assignments on each of these three variables have high concordance with one another. Highest concordance occurs between total SES and capital (80 percent agreement), Kendall's tau-b $=47.57, p \leq .001$. Assignment to levels of material consumption also agrees significantly with the assignment to total SES (65 percent agreement), Kendall's tau- $\mathrm{b}=25.67, p \leq .001$, and capital (52 percent agreement), Kendall's tau- $\mathrm{b}=12.26, p \leq .001$. As expected, these group assignments are significantly correlated with Hollingshead's (1957) SES ratings (relying on candles for light at night and paraffin for cooking). Additional data supporting the validity of these classifications are presented in Table 2. This table shows the expected pattern of significantly increasing resources and possessions from the low- to the high-SES groups. Using the South African government estimates of a 40 percent black poverty rate, the bottom third of our distribution might be considered an impoverished group. The resource profile presented in Table 2 of the low-SES group with a 50 percent rate of childhood hunger, 80 percent lacking material assets and limited possession of expensive consumer goods supports this claim.

\section{Relationship between SES and community safety}

The low-, moderate- and high-SES groups are distributed evenly between the safe and unsafe communities. As Table 2 shows, the proportions of each SES group living in safe and unsafe communities are similar. For the low-SES group, 170 live in unsafe communities and 40 (19 percent of total) live in safe communities. For the moderate-SES group, 168 live in unsafe communities and 46 ( 21 percent of total) live in safe communities. For the high-SES group, 148 live in unsafe communities and 53 (26 percent of total) live in safe communities. These differences are non-significant, $\xi^{2}(2)=.19$, NS. A similar pattern is observed for the relationship between the three-level categorical variables based on the capital and consumption scales. For the capital groups, the proportions of low-, moderate- and highcapital groups living in safe communities are not significantly different (20 percent, 20 percent and 26 percent respectively), $\xi^{2}(2)=.18$, NS. The same is true for the material consumption groups (18 percent, 22 percent and 26 percent respectively), $\xi^{2}(2)=.32$, NS. However participants in unsafe communities had marginally lower standard SES scores $(M$ $=49.5$ vs $51.6, t(623)=2.2, p<.05)$ and higher mean Hollingshead scores $(M=3.6$ vs 3.4, $t(623)=2.4, p<.05)$, which represent a lower SES classification than participants from safe communities. Lower Hollingshead scores indicate a higher SES classification. These mean comparisons of safe and unsafe communities on HESSI standard scores and Hollingshead classification ratings reveal relationships that have statistical significance but the differences between the groups are so small that they lack practical meaning.

\section{The South African Child Assessment Schedule}

The South African Child Assessment Schedule (SACAS) is a structured questionnaire for assessment of behavioral disorders, emotional dysregulation, social competence and academic adjustment. Instrument development took place in steps that included: (1) creating an initial pool of items based on the DSM IV, ICD-10 and child behavior rating scales; (2) revising items to fit the context of socialization and idiomatic usage in South Africa; (3) translation of items; (4) constructing scales using factor analysis; and finally (5) assessing the validity and reliability of scales.

Items were developed using the ICD-10 and DSM IV criteria for emotional and conduct problems as a guideline. Initially, they were patterned after items included in scales commonly used in the US, namely: the ACQ, a national survey of problems and competencies conducted on a representative sample of American children that combines the Achenbach, Conners and Quay scales (Achenbach et al., 1991); the Achenbach Child Behavior Checklist (CBCL; Achenbach, 1991) and the Problem Behavior Index (Zill, 1985) collected as part of the Child Health Supplement to the National Health Interview Surveys in 
1981, 1988 and 1992. Thus, items represented a form of collective wisdom about symptoms that trigger mental health service referrals by parents, teachers and pediatricians and/or that are observed in children so referred. Given the shared focus and purpose of these scales, there is considerable overlap of items across scales. In focus group discussions, South African parents and preschool teachers suggested additional items to assess problems of adjustment in young children. These focus groups also commented on items under consideration and suggested ways to improve the relevance, clarity and wording. The final questionnaire included 85 items related to internalizing and externalizing problems. Just as the scales referenced above are closely related in content, most but not all of the items included for testing in the SACAS have some counterpart in pre-existing scales. For each item, parents rated the frequency with which the child manifested the behavior or affect (never, sometimes, often).

\section{Interview language}

In the initial stage of the project, the questionnaires were designed in English and then translated, back-translated and checked in the three other major languages spoken in South Africa: Zulu, Sotho and Afrikaans. However, because of the close proximity and frequent interactions among speakers of the 11 most common languages in South Africa, the vernacular of urban Africans is not a pure form of any single language. Grammatical forms and vocabulary are shared across languages (Bothma, 1951). In daily usage, words from multiple languages, including English, can be interspersed with one another. For this reason, the wordings used in the interviews were adapted to reflect colloquial speech. In addition, the minority of families whose native language was other than one of the three major language groups were interviewed by a native speaker of that language. The interviewer, in these cases, worked from a questionnaire in the South African language closest to the respondent's native tongue and translated the questionnaires for the families. Once they had received training in the purpose of the interview and the concepts underlying each question, multi-language interviewers reached consensus about phrasings for the questions for each language group that they used consistently.

\section{Interviewers}

Interviews were conducted by five trained multilingual community residents experienced in collecting similar data from earlier panels of the BTT. Each was assigned to conduct interviews in several communities or suburbs that were often divided on the basis of language. For the sake of safety, they most often worked in pairs. The interviewers completed a 2-week training sequence that focused on concepts of childhood developmental psychopathology and parent-child socialization and relationships. Part of the training included supervised practice in administration of the interview. Each interviewer was observed administering the questionnaire, and corrective feedback was provided. No one was permitted to conduct interviews with children until she or he had met the standard of competence in presentation of questions.

\section{Procedures}

The most recent addresses of participating families were generated from the main registrar for the BTT study. Families were called or contacted in person, and an interview time was set up. Interviewers visited mothers' homes and read questions aloud to them to which they responded. Interviewers wrote down the mothers' responses on the questionnaires along with notes, comments and observations about the parents' behavior. Any notes of inconsistency were queried, and mothers were asked to help the interviewer clarify the discrepancy. Items on economic status were left until last. In all, the interviews took approximately 75 minutes. Families were not reimbursed for the interviews, however they were given a calendar that was developed by the program. In some cases, parents' work 
schedules did not permit them to be interviewed at home, and alternatively, families were invited to come to Chris Hani/Baragwanath Hospital - the main public hospital serving Soweto. When parents came to the hospital for the interview, they were reimbursed for travel costs and provided with refreshments.

\section{Clinical cases}

For the sake of rapport and maintaining the relationship with parents and children, administration of the HESSI and the SACAS was embedded within a more extensive conversation with parents about how they and the child were doing. As part of the ethical contract with families and children, when parents expressed concern about some aspect of their child's development, or when an interviewer noted serious problems, a case conference was conducted. Initial concerns ranged from emotional and behavioral difficulties to problems of language and perceptual problems, and chronic somatic complaints such as watery eyes, skin rashes and headaches. Language problems were referred to a speech disorders clinic and abuse/neglect cases were referred to protective services. On the basis of the evidence reported in case conferences and a subsequent clinical evaluation, 77 children were designated as cases on the basis of discernible psychological problems (mostly conduct problems). These determinations were made independent of the results on the SACAS. Additional children (approximately 29) were not designated as cases for our purposes either because the reported condition did not seem serious enough to warrant follow-up or was primarily a physical complaint for which help was already available through the primary health care clinic.

\section{Results}

\section{Scale development}

Parent responses to the symptoms of internalizing and to externalizing symptoms were factor analyzed separately using CBCL scales as a guide for item designation. For both groups items were factor analyzed using Principal Components Analysis routines available in SPSS Version 8. Extracted factors were rotated using Varimax procedure with Kaiser normalization. A minimum of .30 was established for factor loadings. Two factors were extracted from the analysis of internalizing symptoms in three iterations. This solution accounted for 38 percent of the total variance. In all, six items met the minimum score criterion for anxiety (factor I) and seven for depression (factor II) with one item overlapping the two factors (see Table 3). Cronbach's alpha estimates of internal consistency were .63 for anxiety and .66 for depression. As many other studies have found there is a high correlation between anxiety and depression $(r=.62)$. When items are combined into a single scale, Cronbach's alpha for the combined scale improves to .75 .

A three-factor solution emerged from the analyses of externalizing items and accounted for 32 percent of the variance (see Table 4). The rotated factors converged in four iterations. These are labeled: aggression, self-regulation and opposition/defiance. Aggression (factor I) includes 11 items pertaining to fighting and a general disregard for the physical welfare of others. Estimates of internal consistency are in the acceptable range (Cronbach's alpha is .79 and the intra-class correlation coefficient is .80). Self-regulation includes nine items related to behavioral volatility and emotional lability. Estimates of internal consistency are moderate (Cronbach's alpha is .68 and the intra-class correlation coefficient is .70). Opposition/defiance includes five items related to compliance and acceptance of authority and rules. Because of the small number of items, estimates of internal consistency are marginal (Cronbach's alpha is .58 and the intra-class correlation coefficient is .61). Comparisons were also made between the scale scores of the subgroup of children identified as needing clinical services and other children. The referred clinical group $(N=77)$ had 
significantly higher means scores than the non-clinical group on all of the scales (see Table 5).

\section{SACAS and demographic variables}

Pearson product moment correlations were computed to assess the relationship between demographic characteristics and the five SACAS scales. Only one of 15 correlations computed are significant. Mother's age and father's absence were not significantly correlated with any of the scales. Family size was correlated only with depression $(r=.10, p$ $\leq .05$ ). This correlation must be interpreted conservatively since it may be due to chance. In addition, the relationships between gender of the child and SACAS scale scores were evaluated using a one-way ANOVA. Gender was not significant for anxiety, depression or self-regulation. However, boys scored significantly higher than girls on aggression, $M=$ 11.67, $(\mathrm{SD}=5.1)$ vs $M=10.59,(\mathrm{SD}=5.1), F(1,623)=13.0, p \leq .001$ and on opposition, $M$ $=1.64,(\mathrm{SD}=1.6)$ vs $M=1.47,(\mathrm{SD}=1.5), F(1,623)=8.3, p \leq .01$.

\section{MANOVA analyses}

Examination of the relationship between SES and children's psychological functioning began with one-way MANOVAs in which the five-scale scores for behavioral and emotional problems were the dependent variables and the three SES variables (capital, material consumption and total) were the independent variables. The overall MANOVAs for capital and total were not significant using the Wilks lambda criterion, but the Material Consumption factor was, $F(5,618)=2.93, p \leq .001$. Inspection of the univariate results show that means scores on both opposition and self-regulation differ significantly by consumption groups (see Table 6). In addition, Scheffe post-hoc tests were computed to analyze further the source of the differences on opposition and self-regulation. Contrary to expectations, children from households with the lowest level of material resources are rated as less oppositional than children in households with moderate levels of material consumption, $p \leq$. 05. They also have fewer problems of emotional self-regulation than children from households with the greatest access to material goods, $p \leq .001$. No other group differences were observed.

Introduction of the community safety variable moderates the observed effect of consumption. A two-way MANOVA was computed using the five-scale psychological problem scales as dependent variables, and the consumption group (three levels - low, moderate and high) and this time community safety (two levels - safe and unsafe) as independent variables. As expected, the mean child problem scores differed significantly by level of community safety using the Wilks lambda criterion, $F(4,614)=4.65, p \leq .000$. However, the overall multivariate effect for the consumption group is not significant $(F(10,614)=1.24, \mathrm{NS})$; nor is the multivariate effect for the interaction of consumption and safety $(F(10,614)=1.56, \mathrm{NS})$. Inspection of the univariate results reveal significant effects for community safety on all five scales. Table 7 presents the means and univariate test results for each of these scales by community safety. These data show that children growing up in unsafe communities have significantly higher scores on anxiety, depression, aggression, opposition and problems of self-regulation than children raised in communities rated by experts as safe. Similar analyses were conducted to test for the significance of the interactions between safety and SES (capital and total) on the five scales. These interactions were not significant. Although there are differences among the consumption and among the community safety groups in the number of cases as reported in Tables 6 and 7, their variances are very similar. It is unlikely that validity of inferences about significant differences are undercut for this reason. 


\section{Discussion}

Children's behavioral and emotional functioning was assessed using the SACAS, a parental report instrument developed for use in South Africa. A notable limitation of this approach is that it depends entirely on caretakers - mostly mothers - for information about children's functioning. Skepticism about exclusive reliance on parental reports is warranted on several grounds. Parents' sense of danger, their distress from poverty or differences among parents in what they regard as problems may influence reports of their children's behavioral health. Consequently, the results reported here may reflect parental attitudes and stress responses as much as they reflect children's adjustment. On the other side of this issue, studies employing multiple raters of children's adjustment show small rater effects which do not explain much of the variance in the reports of children's behavior (Achenbach and Edelbrock, 1983). Moreover, our data on the psychometric properties of the SACAS suggest that a reasonable case can be made for its reliability and to a limited extent for its validity.

Predictions of the impact of adverse social conditions such as low SES and community violence on behavioral and emotional adjustment as measured by the SACAS are only partially confirmed. Community safety is associated with child outcomes as is the material consumption indicator of SES. Poverty clearly does not have strong effects on the emotional functioning and behavioral regulation of young South African children. Moreover, when effects do occur they run counter to the conventional wisdom about the adverse impact of poverty on children. In contrast to the predictions of lower self-regulation and conduct problems, young children from materially disadvantaged households actually have fewer problems with respect to opposition and self-regulation than their more advantaged counterparts. Perhaps the experience of material deprivation chastens children, engenders a greater appreciation of parents in view of their struggles to provide for them. Perhaps material hardship dampens the sense of personal efficacy, autonomy and entitlement that encourage self-assertion, opposition to authority and the tendency to indulge one's wishes and impulses.

The absence of main and interaction effects may mean that community safety could be responsible in part for the relationship observed between low SES and child outcomes in the US, where the two are often confounded. Other factors may explain the weak confirmation of a relationship between SES and problems of adjustment in this sample of South African 6-year-olds. First, most of the US studies are conducted on older children and adolescents. It is possible that the effects of poverty and low SES are cumulative and do not strongly manifest themselves until later in life. Alternatively, low SES may be a very different phenomenon in South Africa than it is in the US. In South Africa, poverty affects as much as 40 percent of the black population and the poor are not segregated as much. Low SES may not be a stigmatizing condition in South Africa and thus may not result in self-denigration and alienation as it may in the US. Moreover, because low- and high-SES families live in proximity and often have a common ethnic identity, their shared community environment, cultural mores and socialization practices may be more important for child outcomes than differences in their material circumstances.

This study reinforces the importance of violence and behavioral health as a concern during the formative preschool years. Community danger in South Africa is associated with elevated behavioral and emotional problem scores. Children growing up in violent circumstances frequently experience heightened arousal, emotional distress and social loss. In the face of such distress, children may acquire responses such as aggression, bullying, social indifference, premature self-reliance and low responsiveness to direction from adults. Mood and behavior problems might be interpreted as undesirable but defensive adaptations to these conditions. This pattern of adaptation does not augur well for the child's future. 
Adjustment problems arising during this period as a consequence of community danger such as sadness, fear, aggression, oppositional behavior and impairment of social relations, if left unchecked, presage a life-long pattern of difficulties in the psychological and physical arena. These behavioral threats require the same level of attention and commitment of resources devoted to the control and eradication of other public health threats to children such as infectious diseases. Early and sustained intervention can make a demonstrable difference in reducing the risk of difficulty as the child matures. There is no dearth of very promising program ideas that could be implemented. Community development, mentoring, after-school tutoring and recreation programs, social skills training, school-based affective education and family support programs are but a few approaches that are worth testing as preventive solutions to these potential problems.

\section{References}

Achenbach, TM. Manual for the Child Behavior Checklist/4-18 and 1991 Profiles. Burlington: Department of Psychiatry, University of Vermont; 1991.

Achenbach, TM.; Edelbrock, C. Manual for the Child Behavior Checklist and Revised Child Behavior Profile. Burlington: Department of Psychiatry, University of Vermont; 1983.

Achenbach TM, Howell CT, Quay HC, Conners CK. National Survey of Problems and Competencies among Four- to Sixteen-Year-Olds: Parents' Reports for Normative and Clinical Samples. Monographs of the Society for Research in Child Development. 1991; 56(3):v-120. No. 225.

Barbarin OA, Khomo N. Indicators of Economic Status and Social Capital in South African Townships: What Do They Reveal about the Material And Social Conditions In Families Of Poor Children? Childhood. 1997; 4(2):193-222.

Barbarin, OA.; Richter, L. Mandela's Children: Growing up in Post-Apartheid South Africa. New York: Routledge; 2000.

Bothma, C. n Volkekundige ondersoek na die aard en onstaanoorsake van tsotsigroepe en hulle aktiwiteite soos gewind in die stedelike gebied van Pretoria [An Anthropological Enquiry into the Nature and Circumstances of Origin of Street-Gangs and their Activities in the Urban Area of Pretoria]. University of Pretoria; 1951. unpublished master's thesis

Brooks-Gunn J, Duncan G. The Effects of Poverty on Children. The Future of Children: Children and Poverty. 1997; 7:55-71.

Burman, S.; Reynolds, P., editors. Growing Up in a Divided Society: The Contexts of Childhood in South Africa. Evanston, IL: Northwestern University Press; 1986.

Cairns R, Dawes A. Children: Ethnic and Political Violence - A Commentary. Child Development. 1996; 67(1):129-39.

Capaldi, DM.; Patterson, GR. Interrelated Influences of Contextual Factors on Antisocial Behavior in Childhood and Adolescence for Males. In: Fowles, DC.; Sutker, P.; Goodman, SH., editors. Progress in Experimental Personality and Psychopathology Research. New York: Springer; 1994. p. $165-98$.

Dryfoos, JG. Adolescents at Risk: Prevalence and Prevention. New York: Oxford University Press; 1990.

Duncan GJ, Brooks-Gunn J, Klebanov PK. Economic Deprivation and Early-Childhood Development. Child Development. 1994; 65:296-318. [PubMed: 7516849]

Entwistle DR, Astone NM. Some Practical Guidelines for Measuring Youth Race/Ethnicity and SocioEconomic Status. Child Development. 1994; 65:1521-40.

Felner RD, Brand S, DuBois DL, Adan AM, Mulhall PF, Evans EG. Socioeconomic Disadvantage, Proximal Environmental Experiences, and Socioemotional and Academic Adjustment in Early Adolescence: Investigation of a Mediated Effects Model. Child Development. 1995; 66:774-92. [PubMed: 7789201]

Gore S, Aseltine RH, Coldon ME. Gender, Social-Relational Involvement, and Depression. Journal of Research on Adolescence. 1993; 3:101-25. 
Guerra NG, Tolan TH, Huesmann LR, Van Acker R, Eron LD. Stressful Events and Individual Beliefs as Correlates of Economic Disadvantage and Aggression among Urban Children. Journal of Consulting and Clinical Psychology. 1995; 63:518-28. [PubMed: 7673529]

Hammen, C.; Rudolph, KD. Childhood Depression. In: Mash, EJ.; Barkley, RA., editors. Child Psychopathology. New York: Guilford Press; 1996. p. 153-95.

Hollingshead, AB. Two Factor Index of Social Position. New Haven, CT: Department of Sociology, Yale University; 1957.

McLoyd VC. Socioeconomic Disadvantage and Child Development. American Psychologist. 1998; 53(2):185-204. [PubMed: 9491747]

Osofsky J, Wewers S, Hann DM, Fick AC. Chronic Community Violence: What Is Happening to Our Children? Psychiatry. 1993; 56(1):36-45. [PubMed: 8488211]

Reinherz HZ, Giaconia RM, Pakiz B, Silverman AB, Frost AK, Lefkowitz ES. Psychosocial Risks for Major Depression in Late Adolescence: A Longitudinal Community Study. Journal of the American Academy of Child and Adolescent Psychiatry. 1993; 32:1155-63. [PubMed: 8282659]

Richter LM, Yach D, Cameron N, Griesel RD, deWet T. Enrollment into Birth-to-Ten (BTT): Population and Sample Characteristics. Pediatrics and Perinatal Epidemiology. 1995; 9:109-20.

Richters JE, Martinez PE. Violent Communities, Family Choices, and Children's Changes: An Algorithm for Improving the Odds. Development and Psychopathology. 1993a; 5:5-29.

Richters JE, Martinez P. The NIMH Community Violence Project: 1 Children as Victims of and Witness to Violence. Psychiatry. 1993b; 56(1):7-21. [PubMed: 8488215]

Robertson, B.; Berger, S. Child Psychopathology in South Africa. In: Dawes, A.; Donald, D., editors. Childhood and Adversity: Psychological Perspectives from South African Research. Cape Town: David Phillip; 1994. p. 136-53.

Straker, G. Faces in the Revolution: The Psychological Effects of Violence in Township Youth in South Africa. Athens: Ohio University Press; 1992.

Valez CN, Johnson J, Cohen P. A Longitudinal Analysis of Selected Risk Factors for Childhood Psychopathology. Journal of the American Academy of Child and Adolescent Psychiatry. 1989; 28:861-4. [PubMed: 2808256]

United Nations. The United Nations Human Development Report. New York: UN; 1998.

World Bank. South Africans Rich and Poor: Baseline Household Statistics. Cape Town: Saldru School of Economics; 1994.

Zill, N. Behavior Problem Scales Developed from the 1981 Child Health Supplement to the National Health Interview Survey. Washington, DC: Child Trends; 1985. 


\section{Table 1}

Social, economic and family characteristics of the study sample

\begin{tabular}{lrccc}
\hline & $\mathbf{N}$ & Percentage of total & Unsafe & Safe \\
\hline Gender of child & & & & \\
Boys & 310 & 49.6 & 49.8 & 48.9 \\
Girls & 315 & 50.4 & 50.2 & 51.1 \\
Race & & & & \\
Indian & 4 & 0.6 & 0 & 2.9 \\
Colored & 55 & 8.8 & 11.3 & 0 \\
African & 565 & 90.5 & 88.7 & 97.1 \\
Primary language & & & & \\
Zulu & 240 & 38.7 & 37.1 & 44.5 \\
South Sotho & 113 & 18.2 & 15.7 & 27.0 \\
Tswana & 91 & 14.7 & 16.8 & 7.3 \\
Xhosa & 39 & 6.5 & 6.0 & 7.3 \\
English & 13 & 3.5 & 3.5 & 2.9 \\
Afrikaans & 13 & 3.5 & 7.9 & 6.1 \\
Pedi & 30 & 4.8 & 5.0 & 4.4 \\
Venda/Tsonga & 44 & 7.1 & 7.7 & 5.1 \\
Child hunger & 132 & 21.1 & 20.8 & 22.3 \\
\hline
\end{tabular}


Table 2

Comparison of SES groups on material possessions (percentage possessing item)

\begin{tabular}{|c|c|c|c|c|}
\hline & $\operatorname{Low}(\mathrm{N}=209)$ & Moderate $(\mathrm{N}=210)$ & $\operatorname{High}(\mathrm{N}=201)$ & $\chi^{2}\left(d_{f} f .=2\right)$ \\
\hline Car & $6.7 \%$ & $21.9 \%$ & $51.2 \%$ & $108.1^{* * *}$ \\
\hline Refrigerator & $75.1 \%$ & $93.4 \%$ & $99.0 \%$ & $66.2^{* * * *}$ \\
\hline Microwave & $2.0 \%$ & $4.2 \%$ & $23.9 \%$ & $66.3^{* * * *}$ \\
\hline Telephone & $28.7 \%$ & $61.3 \%$ & $80.1 \%$ & $113.2^{* * *}$ \\
\hline Television & $80.3 \%$ & $96.7 \%$ & $98.0 \%$ & $52.6^{* * * *}$ \\
\hline VCR & $6.8 \%$ & $22.3 \%$ & $54.7 \%$ & $121.9^{* * *}$ \\
\hline Washing machine & $3.8 \%$ & $11.2 \%$ & $48.8 \%$ & $144.1^{* * *}$ \\
\hline Hunger & $50.5 \%$ & $10.7 \%$ & $1.5 \%$ & $168.9^{* * * *}$ \\
\hline Shack/hostel & $7.7 \%$ & $1.0 \%$ & $0.0 \%$ & $38.4^{* * * *}$ \\
\hline Inside toilet & $15.2 \%$ & $31.8 \%$ & $61.7 \%$ & $101.6^{* * *}$ \\
\hline Life insurance & $3.3 \%$ & $18.7 \%$ & $64.2 \%$ & $202.4^{* * * *}$ \\
\hline Savings & $13.3 \%$ & $48.1 \%$ & $85.6 \%$ & $214.6^{* * * *}$ \\
\hline Home ownership & $21.9 \%$ & $46.3 \%$ & $60.2 \%$ & $107.4^{* * * *}$ \\
\hline Mother high school graduate & $5.8 \%$ & $18.4 \%$ & $40.9 \%$ & $126.4^{* * *}$ \\
\hline Mother married & $27.3 \%$ & $40.1 \%$ & $54.6 \%$ & $41.6^{* * * *}$ \\
\hline \multicolumn{5}{|l|}{ Employment status } \\
\hline Unemployed & $44.8 \%$ & $13.0 \%$ & $1.0 \%$ & \\
\hline Unskilled laborer & $37.6 \%$ & $21.1 \%$ & $8.0 \%$ & \\
\hline Skilled laborer & $17.6 \%$ & $44.9 \%$ & $28.8 \%$ & \\
\hline Professional & $0.0 \%$ & $21.1 \%$ & $62.2 \%$ & \\
\hline Residential safety & $28.8 \%$ & $33.1 \%$ & $38.1 \%$ & 3.29 \\
\hline \multicolumn{5}{|l|}{$*^{*}<.05$} \\
\hline \multicolumn{5}{|l|}{$*^{* * *} p<.01$} \\
\hline
\end{tabular}


Table 3

Rotated factor matrix for internalizing symptoms

\begin{tabular}{lcc}
\hline & \multicolumn{2}{c}{ Factor loadings } \\
\cline { 2 - 3 } & Depression & Anxiety \\
\hline Unhappy & .630 \\
Sad & .675 \\
Worries & .645 \\
Withdrawn & .649 & \\
Underactive & .481 & \\
Prefers to be alone & .448 & \\
Sudden changes in mood & .445 & .425 \\
Fears doing something bad & & .758 \\
Guilty & & .738 \\
Has specific fears & & .600 \\
Fearful, anxious & & .461 \\
Worthless, inferior & & 302 \\
\hline
\end{tabular}

Notes: Extraction method: Principal Component Analysis; rotation method: Varimax with Kaiser normalization; rotation converged in three iterations. 
Table 4

Rotated factors for behavioral problems

\begin{tabular}{|c|c|c|c|}
\hline & \multicolumn{3}{|c|}{ Factor loadings } \\
\hline & Aggression & Self-regulation & Opposition \\
\hline Loud, noisy & .683 & & \\
\hline Starts fights & .521 & & \\
\hline Mean & .418 & & \\
\hline Destroys others' possessions & .462 & & \\
\hline Physically attacks others & .462 & & \\
\hline Sullen stubborn & .451 & & \\
\hline Screams & .573 & & \\
\hline Teases others & .394 & & \\
\hline Destroys own things & .426 & & \\
\hline Talks too much & .404 & & \\
\hline Impulsive & .310 & & \\
\hline Sudden changes in mood & & .598 & \\
\hline Suspicious & & .647 & \\
\hline Threatens people & & .611 & \\
\hline Jealous & & .368 & \\
\hline Temper tantrums & & .393 & \\
\hline Irritable & & .494 & \\
\hline Brags & & .427 & \\
\hline Argues & & .453 & \\
\hline Daydreams & & .427 & \\
\hline Disobeys teachers & & & .712 \\
\hline Disobeys parents & & & 649 \\
\hline Poor, negligent with school work & & & .392 \\
\hline Breaks rules & & & .323 \\
\hline
\end{tabular}

Notes: Extraction method: Principal Components Analysis; rotation method: Varimax with Kaiser normalization. Rotation converged in six iterations. 
Table 5

Mean for clinical and non-clinical samples on the SACAS problem and competence scales

\begin{tabular}{|c|c|c|c|c|}
\hline \multirow[b]{3}{*}{ Scales } & \multicolumn{4}{|c|}{ Clinical status } \\
\hline & \multicolumn{2}{|c|}{ Clinical } & \multicolumn{2}{|c|}{ Non-clinical } \\
\hline & $\mathbf{M}$ & $S D$ & $\mathbf{M}$ & $S D$ \\
\hline Anxiety & 4.91 & 2.6 & 2.63 & 2.4 \\
\hline Depression & 6.19 & 2.9 & 2.30 & 2.3 \\
\hline Aggression & 16.12 & 4.0 & 10.42 & 4.9 \\
\hline Self-regulation & 11.65 & 3.5 & 5.89 & 3.7 \\
\hline Opposition & 2.92 & 1.9 & 1.26 & 1.4 \\
\hline
\end{tabular}




$$
\begin{aligned}
& \begin{array}{ll}
0 & 0 \\
0 & 0 \\
\frac{0}{0} & 0 \\
& 0
\end{array}
\end{aligned}
$$

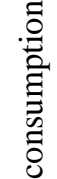

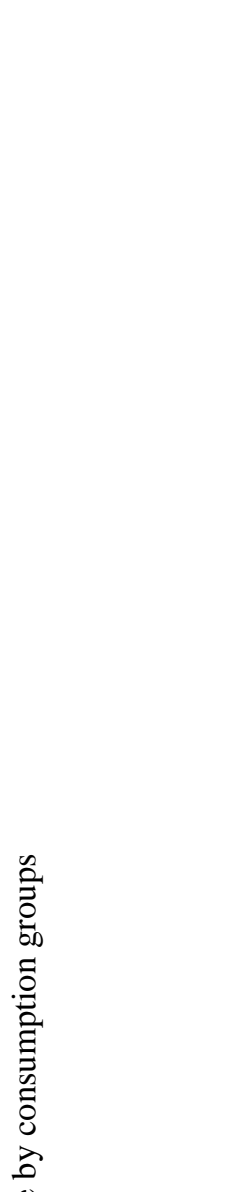

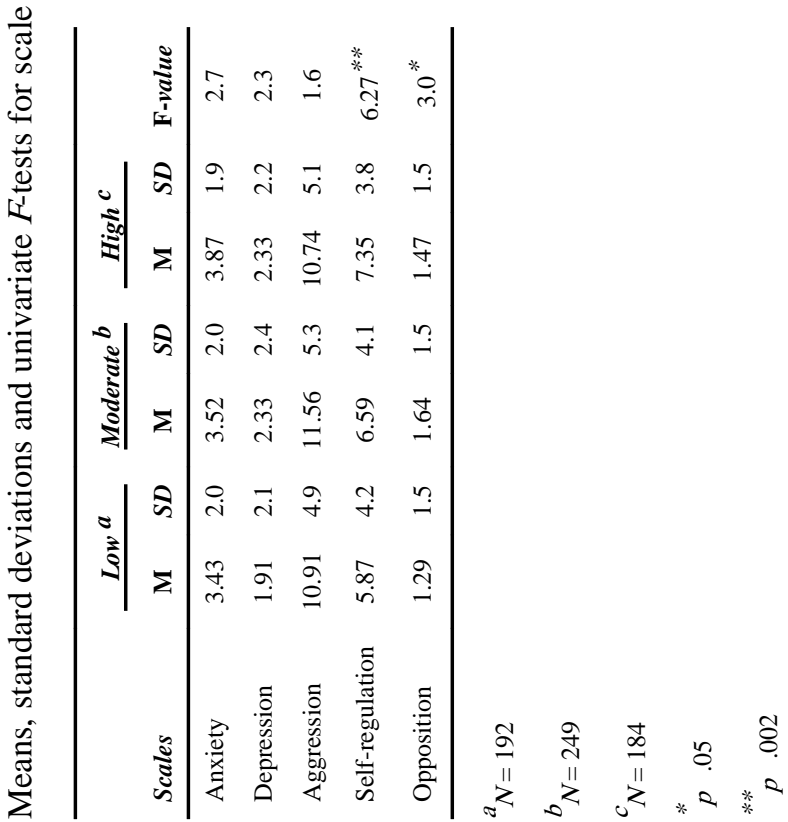




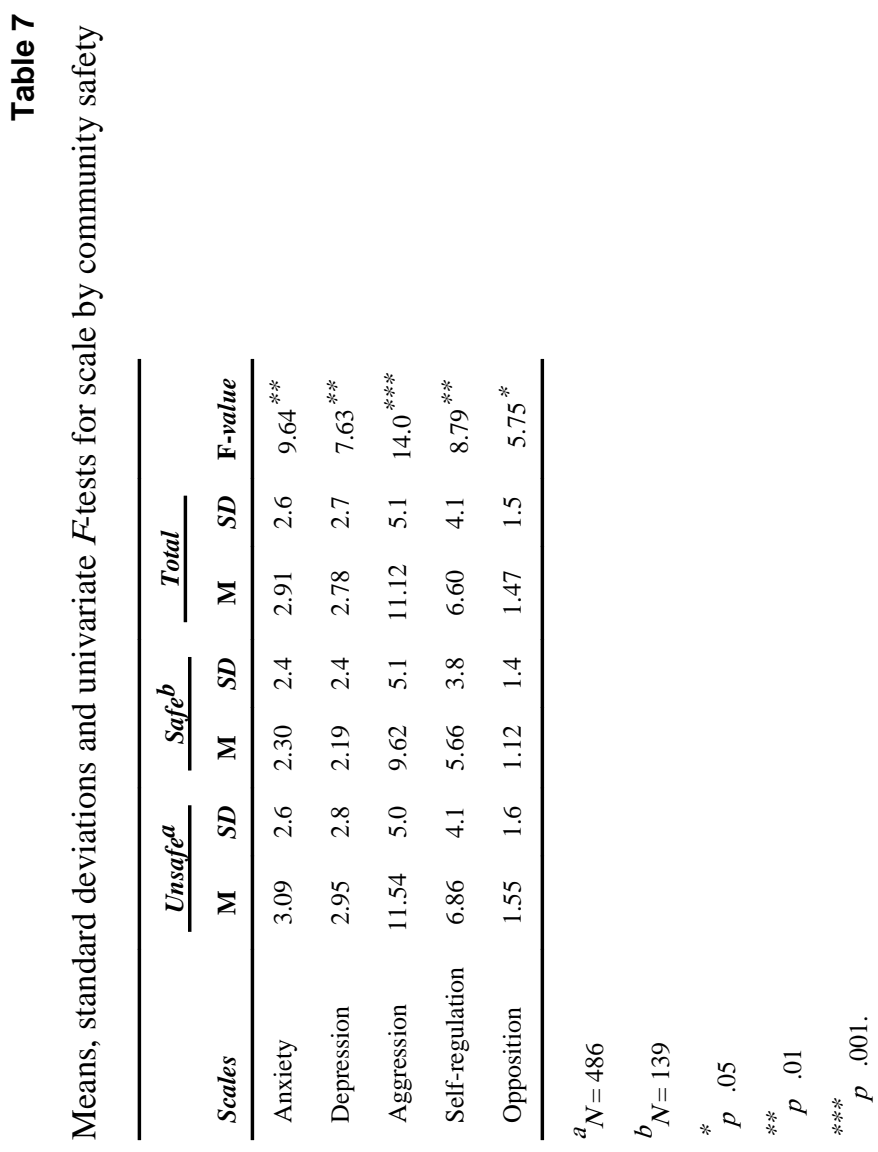

